\title{
Influence of lead and zinc oxides on the radiation shielding properties of tellurite glass systems
}

\begin{abstract}
The radiation shielding properties of $\mathrm{xPbO}-(100-\mathrm{x}) \mathrm{TeO} 2, \mathrm{x}=10,20$, and $30 \mathrm{~mol} \%$ binary glasses and $\mathrm{y}[\mathrm{ZnO}]-(100-\mathrm{y})[70(\mathrm{TeO} 2)-30(\mathrm{PbO})] \mathrm{y}=15,20$, and $25 \mathrm{~mol} \%$ ternary glasses were investigated using Geant 4 simulations and the newly developed Phy-X/PSD program. The glasses' gamma shielding abilities were assessed using their mass attenuation coefficient $(\mu / \rho)$, mean free path (MFP), effective atomic number (Zeff), and half value layer (HVL) values. The neutron shielding ability was evaluated by determining the removal cross-section (RCS) values, which were 0.097, 0.101, and 0.103 cm-1 for binary PbO-TeO2 (PT) glasses and 0.118, 0.116, and 0.114 cm-1 for ternary ZnO-PbO-TeO2 (PTZ) glasses. The gamma and neutron shielding features of the glasses were compared with those of various ordinary concretes and $\mathrm{Pb}$-free, $\mathrm{Pb}$-based, and commercial glasses. The addition of $\mathrm{PbO}$ changed the gamma and neutron properties of the PT glasses, while the addition of $\mathrm{ZnO}$ demonstrated a different trend in the gamma properties of the PTZ glass system.
\end{abstract}

Keyword: Shielding properties; Tellurite glass; Lead oxide; Zinc oxide; Geant4; Phy-X/PSD 